\title{
Awareness, Knowledge, Perceived Benefits, and Barriers Regarding Precision Medicine and Willingness to Participate in a National Registry: Comparison of Cancer Patients and the General Population
}

\author{
Mangyeong Lee \\ SAIHST, Sungkyunkwan University \\ Juhee Cho \\ Samsung Medical Center, Sungkyunkwan University School of Medicine \\ Sun-Young Kong \\ National Cancer Center \\ Junghee Yoon \\ SAIHST, Sungkyunkwan University \\ Danbee Kang \\ SAIHST, Sungkyunkwan University \\ Kui Son Choi \\ National Cancer Center Graduate School of Cancer Science and Policy \\ Soo-Yong Shin \\ Samsung Medical Center, Sungkyunkwan University School of Medicine \\ Hwa Jeong Seo \\ Gachon University
}

So-Youn Jung

National Cancer Center

Myong Cheol Lim

National Cancer Center Graduate School of Cancer Science and Policy

Eun Sook Lee

National Cancer Center

Yoon Jung Chang ( $\nabla$ eunice.ncc@gmail.com )

National Cancer Center Graduate School of Cancer Science and Policy

Research Article 
Keywords: Precision medicine, Personalized medicine, Patient participation, Patient-centered care, Crosssectional study, Clinical ethics

Posted Date: March 19th, 2021

DOI: https://doi.org/10.21203/rs.3.rs-289894/v1

License: (1) This work is licensed under a Creative Commons Attribution 4.0 International License. Read Full License

Version of Record: A version of this preprint was published at JMIR Cancer on March 12th, 2019. See the published version at https://doi.org/10.2196/13984. 


\section{Abstract \\ Background}

Precision medicine (PM) is a growing area of interest in cancer care. However, relatively little is known about the public attitudes toward PM and the factors associated with the willingness to participate in the construction of national registries for PM.

\section{Methods}

A cross-sectional survey was conducted with 1,500 cancer patients and 1,496 general population in South Korea from November 2016 to February 2017. We evaluated cancer patients' awareness, knowledge, as well as perceived benefits and barriers regarding precision medicine (PM), and their willingness to participate in a national registry for PM, compared to the general population. Logistic regression analysis was performed to identify the factors associated with the willingness to participate in a national registry for PM.

\section{Results}

1,500 cancer patients and 1,496 general population were recruited for the study. Cancer patients were less likely to have heard of PM than the general population $(20.0 \%$ and $33.1 \%, P<.001), 34.2 \%$ of the participants knew the correct definition of PM. Cancer patients were more likely to However, fewer study participants in both groups said they would like to share their personal health data for PM, compared to the number of people who are willing to participate. Cancer patients (aOR 2.98, 95\% Cl, 2.47-3.61), participants who had heard of PM before (aOR 1.40, 95\% Cl, 1.00-1.95), had greater perceived benefits (aOR, 2.48, 95\% Cl, 1.88-3.27) and fewer perceived barriers (aOR 1.57, 95\% Cl, 1.18-2.08) regarding PM were more likely to have the willingness to participate in the registry compared to those who did not.

\section{Conclusions}

Cancer patients were more likely to have greater perceived benefits of PM and higher willingness to participate in the related study than the general population. However, both two groups were still informed about PM well. This study suggests considering the provision of information and education about PM such as expected values and required roles both to the general population and cancer patients.

\section{Introduction}

Precision medicine (PM) is a growing area of interest in cancer care. In 2015, the Precision Medicine Initiative (currently known as All of Us), with $\$ 215$ million in funding, initiated research to accelerate biomedical discoveries [1]; $\$ 70$ million of this fund was allocated to the National Cancer Institute for 
increased efforts in identifying the genomic drivers of cancer and the application of new knowledge in developing more effective treatments [1]. The obtained knowledge on the oncogenic mechanisms has enabled the provision of tailored medical care depending on individual variability, with advances in diagnosis and treatment $[2,3]$. The Cancer Genome Atlas has been helpful in defining the genomic features unique to different cancers and developing specific therapies targeted at those features [4]. Other cancer-related studies have also developed many targeted therapies resulting in increased clinical benefit [5-7]. However, PM in cancer care is not yet a part of routine care for most patients.

As part of PM, it is important to collect a variety of biomedical data including those pertaining to genomic, behavioral, physiological, and environmental parameters [8]. Many countries, including the United States (US) and the United Kingdom, are constructing national registries or large cohorts for PM [9-12]. Additionally, major efforts are being driven in a bid to increase the level of awareness on PM in the general population, as voluntary participation is essential for the success of national registries $[10,13$, 14]. Yet, the participation rates in national registries vary from $5-90 \%[15,16]$, and relatively little is known of the public attitudes toward PM and the factors associated with participation in the construction of national registries for PM.

Although the terms 'precision medicine' and 'personalized medicine' are used interchangeably, the former may be new both to cancer patients and the general population [17]. Most previous studies evaluated peoples' attitudes towards genetic testing as a part of personalized medicine and included a single stakeholder, either patients or the general population. Few studies have evaluated cancer patients' knowledge and perception of PM with limited sample size. This may provide the just partial information on clearly understanding the holistic reactions of people toward PM that can be founded at the initial stage. Therefore, to help people including patients to accept, utilize and receive adequate benefits from $\mathrm{PM}$, it needs to carry out the integrated evaluation regarding various aspects of PM with the large scale of a sample. This study aimed to evaluate cancer patients' awareness, knowledge, as well as perceived benefits and barriers regarding PM, and their willingness to participate in a national registry for PM, compared to the general population.

\section{Methods}

\subsection{Participants}

This cross-sectional survey involved face-to-face interviews administered by trained researchers. At the Korean National Cancer Center and the Samsung Medical Center in Seoul-Metropolitan area, South Korea, 1,500 consecutive cancer patients were recruited at outpatient clinics or inpatient rooms from November 2016 to February 2017. The patients had to be at least 18 years of age to be eligible for this study, and have histologically confirmed stomach, breast, lung, gynecological, or colon cancer. The participants comprised 300 patients with cancer types that met our criteria. At an outpatient clinic and inpatient room, trained researchers explained the research and its objectives to the participants and obtained informed consent. Participants were then asked to answer the survey questionnaire. 
In addition, we recruited a sample that was representative of the Korean population as the control group. Individuals from the general population who were at least 18 years of age and did not have cancer were eligible for inclusion into the control group. To obtain a representative sample of the Korean population, we used the quota sampling method which takes the distribution assembled by sex, age, and area of residence into account. We conducted home visit or street survey and trained researchers explained the study details and administered the interviews when people agreed to participate. All study participants provide written informed consent. We first recruited 1,500 people; however, four participants with a history of cancer were excluded. A total of 1,496 people were finally included.

The study was approved by the institutional review boards of the National Cancer Center Korea (NCC 2016 - 0256) and the Samsung Medical Center (SMC 2016-12-040).

\subsection{Measurements}

As there was no specific questionnaire to assess PM-related awareness, knowledge, and perceived benefits and barriers, we developed a questionnaire based on a literature review and experts' opinions. Further, we conducted a pilot study to evaluate the length and logic of the questionnaire before the actual survey. In total, 23 questions were developed to assess awareness $(n=2)$, knowledge $(n=1)$, perceived benefits $(n=7)$ and perceived barriers $(n=3)$, and willingness to participate in a national registry for PM $(n=4)$.

To assess the level of awareness on PM, we asked participants if they had heard about PM before (dichotomous questions; yes or no); if yes, we asked them where they had heard of it. Participants were provided multiple choices pertaining to the source, such as print materials (books, magazines, and brochures), the Internet, mass media (television and newspaper), healthcare professionals, peers, and family members [18]. The level of PM-related knowledge was evaluated by asking participants to choose the correct definition of PM ("An emerging clinical approach that takes into account individual variability for each person") from four definitions. We developed three incorrect definitions based on common misunderstandings that were determined from the qualitative interviews of the patients: "Use of new tools with more fine-tuned measurement"; "Advanced diagnosis and care using nanorobots that can be implanted in the human body"; "Clinical care that patients could receive regardless of time and place".

A one-page handout that explained the definition and examples of PM (S1 File) was provided so participants could answer questions regarding the perceived benefits and barriers, with seven and three questions, respectively. The perceived benefits comprised diagnosis-related items $(n=3)$ and treatmentrelated items $(n=4)$, while the perceived barriers comprised possible factors (cost, applicability of actual practice, and privacy) after the implementation of PM. While composing each item, we considered the issues frequently mentioned in domestic or foreign press, and informational web material on PM; the issues and the material predominantly focused on the clinical promise of PM and the challenge or preparation associated with its implementation in practice [19-21]. Participants were asked to what extent they agreed with the statements on PM, and a 4-point Likert scale was employed ( 1 = strongly disagree, 2 = disagree, 3 = agree, 4 = strongly agree). 
We then asked the participants about their willingness to participate in a national registry for PM. In addition, we asked study participants about their willingness to share personal health data for PM and type of data they would like to share. Type of personal health data included genetic information, physical characteristics (weight, height, body composition, and etc.), medical records, and lifelog data (nutrition intake, physical activity, sleep pattern, and etc.). Finally, data on participants' sociodemographic characteristics, including sex, age, educational level, household income, and area of residence were collected. For cancer patients, we also collected data on the cancer type, stage at diagnosis, treatment status, and time since diagnosis. Participants in the control group were separately asked about the presence of comorbidities including a history of cancer.

\subsection{Statistical analysis}

Student's T-test and $\chi^{2}$ test were used to ascertain differences between the patients and general population. To identify factors associated with the willingness to participate in a national registry for PM, we performed multivariable logistic regression analysis, adjusted for socio-demographics factors (sex, age, education level, and area of residence), awareness (heard of it before; yes or no), knowledge on PM (chose the right PM definition; adequate or limited), and attitudes (benefits and barriers). All statistical analyses were performed using STATA 14.0 (Stata Corp LP, College Station, Texas, USA) and R 3.3.3 (R foundation, Austria), and statistical significance was set at $P<0.05$.

\section{Results}

\subsection{Characteristics of the study population}

The mean ages of the cancer patients and those in the control group were 56.0 and 43.0 years, respectively $(P<0.001$; Table 1$)$. The cancer patients were more likely to be female $(P<0.001)$, older $(P<$ $0.001)$, have a high school and lower education $(P<0.001)$ and live in a non-metropolitan city $(P<0.001)$ than those in the general population. Of the cancer patients, $44.3 \%$ were under active treatment, and the mean time since cancer diagnosis was 2.7 years (standard deviation, 2.9, S1 Table). 
Table 1

Characteristics of the study population $(n=2,996)$

\begin{tabular}{|c|c|c|c|}
\hline & Cancer patients & General population & \\
\hline & $(n=1,500)$ & $(n=1,496)$ & \\
\hline & $n(\%)$ & $n(\%)$ & $P$ value \\
\hline Age (years), mean (SD) & $56.0(11.1)$ & $43.0(12.0)$ & $<0.001$ \\
\hline Sex & & & $<0.001$ \\
\hline Male & $599(39.9)$ & $773(51.7)$ & \\
\hline Female & $901(60.1)$ & $723(48.3)$ & \\
\hline Education level & & & $<0.001$ \\
\hline$\leq$ High school & $924(61.6)$ & $797(53.3)$ & \\
\hline$\geq$ College & $576(38.4)$ & $699(46.7)$ & \\
\hline Monthly household income & & & $<0.001$ \\
\hline$<\$ 3,000$ & $668(44.5)$ & $261(17.4)$ & \\
\hline$\$ 3,000-\$ 4,999$ & $592(39.4)$ & $864(57.7)$ & \\
\hline$\geq \$ 5,000$ & $240(16.0)$ & $371(24.8)$ & \\
\hline Area of residence ${ }^{a}$ & & & $<0.001$ \\
\hline Metropolitan city & $939(62.6)$ & $1,051(70.3)$ & \\
\hline Non-metropolitan city & $558(37.2)$ & $445(29.7)$ & \\
\hline \multicolumn{4}{|c|}{ a A metropolitan city is a city with a population of over 500,000} \\
\hline SD, standard deviation & & & \\
\hline
\end{tabular}

\subsection{Awareness and knowledge on PM}

Cancer patients were less likely to have heard of PM than those in the general population $(20.0 \%$ and $33.1 \%$, respectively, $P<.001$; Table 2 ). More than half of the cancer patients had heard of PM from healthcare professionals (54.0\%), while most of those in the general population had heard of it through mass media (76.0\%). Only $34.2 \%$ of the participants knew the correct definition of PM and cancer patients (35.1\%) were likelier to know the correct definition than the general population $(33.2 \%, P=0.02)$. The number of cancer patients and the general population who had heard of PM and knew what it is were $8.47 \%$ and $11.9 \%$, respectively (data not shown). About half of the participants incorrectly answered that PM is "a medicine that uses new tools with more fine-tuned measurement." 
Table 2

Awareness and knowledge on precision medicine $(n=2,996)$

\begin{tabular}{|c|c|c|c|c|}
\hline & $\begin{array}{l}\text { Cancer } \\
\text { patients }\end{array}$ & $\begin{array}{l}\text { General } \\
\text { population }\end{array}$ & & \\
\hline & $\begin{array}{l}(n= \\
1,500)\end{array}$ & $(n=1,496)$ & & \\
\hline & $\mathrm{n}(\%)$ & $\mathrm{n}(\%)$ & $\begin{array}{l}P \\
\text { value }\end{array}$ & $\begin{array}{l}\text { Adjusted } \\
\text { P value }^{\text {d }}\end{array}$ \\
\hline Heard of it before (yes) ${ }^{a}$ & $\begin{array}{l}300 \\
(20.0)\end{array}$ & $495(33.1)$ & $\overleftarrow{0.001}$ & $<0.001$ \\
\hline Healthcare professionals & $\begin{array}{l}162 \\
(54.0)\end{array}$ & $58(11.7)$ & $<.001$ & $<0.001$ \\
\hline Mass media ${ }^{b}$ & $\begin{array}{l}128 \\
(42.7)\end{array}$ & $376(76.0)$ & $\overleftarrow{0.001}$ & $<0.001$ \\
\hline Internet & $\begin{array}{l}102 \\
(34.0)\end{array}$ & $223(45.1)$ & 0.002 & 0.529 \\
\hline Print material ${ }^{\mathrm{C}}$ & $\begin{array}{l}40 \\
(13.3)\end{array}$ & $63(12.7)$ & 0.805 & 0.698 \\
\hline Peers and family & $28(9.3)$ & $130(26.3)$ & $<.001$ & $<0.001$ \\
\hline \multicolumn{5}{|l|}{ Definition of precision medicine (single response) } \\
\hline $\begin{array}{l}\text { An emerging clinical approach taking into account } \\
\text { individual variability for each person (correct) }\end{array}$ & $\begin{array}{l}526 \\
(35.1)\end{array}$ & $497(33.2)$ & 0.287 & 0.018 \\
\hline $\begin{array}{l}\text { Use of new tools with more fine-tuned } \\
\text { measurement }\end{array}$ & $\begin{array}{l}738 \\
(49.2)\end{array}$ & $703(47.0)$ & 0.226 & 0.649 \\
\hline $\begin{array}{l}\text { Advanced diagnosis and care using nanorobots } \\
\text { that can be implanted in human body }\end{array}$ & $\begin{array}{l}209 \\
(13.9)\end{array}$ & $267(17.8)$ & 0.003 & 0.015 \\
\hline $\begin{array}{l}\text { A clinical care that patients could receive } \\
\text { regardless of time and place. }\end{array}$ & $27(1.8)$ & $29(1.9)$ & 0.780 & 0.980 \\
\hline \multicolumn{5}{|c|}{$\begin{array}{l}\text { a Mutually inclusive (multiple responses), cancer patients }(n=300) \text { and the general population }(n= \\
\text { 495) }\end{array}$} \\
\hline \multicolumn{5}{|l|}{${ }^{\mathrm{b}}$ Mass media: TV and newspapers } \\
\hline \multicolumn{5}{|c|}{ c Print material: Books, magazines, and educational brochures } \\
\hline
\end{tabular}

\subsection{Perceived benefits and barriers, and willingness to participate in a national registry for PM}


Most of the cancer patients answered that PM use would improve the accuracy of disease detection $(97.7 \%)$ and disease risk assessment (96.9\%), improve the strength of therapeutic effects (98.3\%), and reduce the risk of side effects or treatment-related complications (92.2\%). While there were some differences between the responses of the cancer patients and those in the general population, the general population also perceived the benefits of PM (Table 3). In terms of perceived barriers, both cancer patients $(88.1 \%)$ and those in the general population $(82.9 \%)$ reported that they were most worried about the increased healthcare costs associated with PM. The cancer patients $(83.7 \%)$ were likelier to believe that the actual practice of PM would require some time than the general population (80.2\%), and they $(64.9 \%)$ were also less likely to perceive privacy concerns as barriers to PM than the general population $(74.5 \%, P<0.001)$. Cancer patients $(77.5 \%)$ were likelier to participate in a national registry for PM than those in the general population $(55.2 \%, P<.001)$. We found that $70.8 \%$ and $39.6 \%$ of cancer patients and general population had the intention to share any health data for their own treatment or others which were lower than those of willingness of participate in a national registry for PM. In terms of type of health data, both cancer patients and the general population were most likely to share lifelog data and least likely to share the medical records. 
Table 3

Perceived benefits and barriers and willingness to participate in a national registry for precision medicine $(n=2,996)$

\begin{tabular}{|c|c|c|c|c|}
\hline & $\begin{array}{l}\text { Cancer } \\
\text { patients }\end{array}$ & $\begin{array}{l}\text { General } \\
\text { population }\end{array}$ & & \\
\hline & $\begin{array}{l}(n= \\
1,500)\end{array}$ & $(n=1,496)$ & & \\
\hline & $\mathrm{n}(\%)$ & $\mathrm{n}(\%)$ & $\begin{array}{l}\mathrm{P} \\
\text { value }\end{array}$ & $\begin{array}{l}\text { Adjusted } \\
\text { P value }^{\mathrm{a}}\end{array}$ \\
\hline \multicolumn{5}{|l|}{ Perceived Benefits ${ }^{b}$} \\
\hline Improved accuracy of disease detection & $\begin{array}{l}1,466 \\
(97.7)\end{array}$ & $1,349(90.2)$ & $<.001$ & $<0.001$ \\
\hline Better disease risk assessment & $\begin{array}{l}1,454 \\
(96.9)\end{array}$ & $1,368(91.4)$ & $<.001$ & $<0.001$ \\
\hline $\begin{array}{l}\text { Reduced performance rate of unnecessary } \\
\text { repeated tests }\end{array}$ & $\begin{array}{l}1,280 \\
(85.3)\end{array}$ & 1,233 (82.4) & $<.001$ & 0.067 \\
\hline $\begin{array}{l}\text { Improved therapeutic effect } \\
\text { due to optimal treatment for individuals }\end{array}$ & $\begin{array}{l}1,475 \\
(98.3)\end{array}$ & $1,350(90.2)$ & $\begin{array}{l}< \\
0.001\end{array}$ & $<0.001$ \\
\hline $\begin{array}{l}\text { Reduced treatment-related side effect or } \\
\text { complication risk }\end{array}$ & $\begin{array}{l}1,383 \\
(92.2)\end{array}$ & $1,253(83.8)$ & $\begin{array}{l}< \\
0.001\end{array}$ & $<0.001$ \\
\hline Increased life expectancy & $\begin{array}{l}1,336 \\
(89.1)\end{array}$ & $1,287(86.0)$ & $<.001$ & 0.032 \\
\hline $\begin{array}{l}\text { Enhanced quality of life } \\
\text { due to tailored health management }\end{array}$ & $\begin{array}{l}1,420 \\
(94.7)\end{array}$ & $1,399(93.5)$ & 0.112 & 0.223 \\
\hline \multicolumn{5}{|l|}{ Perceived Barriers $^{c}$} \\
\hline Increased healthcare cost & $\begin{array}{l}1,322 \\
(88.1)\end{array}$ & $1,240(82.9)$ & $<.001$ & 0.007 \\
\hline $\begin{array}{l}\text { Takes a while to actually practice precision } \\
\text { medicine }\end{array}$ & $\begin{array}{l}1,255 \\
(83.7)\end{array}$ & $1,200(80.2)$ & 0.031 & 0.070 \\
\hline Privacy concern & $\begin{array}{l}973 \\
(64.9)\end{array}$ & $1,115(74.5)$ & $<.001$ & $<0.001$ \\
\hline
\end{tabular}

\footnotetext{
a Adjusted for age (continuous), sex, education, and living area

${ }^{b},{ }^{c}$ The value was calculated after changing the 4-point Likert scale to a dichotomous variable.

${ }^{d}$ Values included the people who responded that they will donate at least one type of health data.
} 


\begin{tabular}{|lllll|}
\hline & $\begin{array}{l}\text { Cancer } \\
\text { patients }\end{array}$ & $\begin{array}{l}\text { General } \\
\text { population }\end{array}$ & & \\
\hline Willingness to participate in a national registry & 1,163 & $826(55.2)$ & $<$ & $<0.001$ \\
for precision medicine (yes) & $(77.5)$ & & 0.001 & \\
Willingness to share personal health data for & 1,062 & $592(39.6)$ & $<$ & $<0.001$ \\
precision medicine (yes) ${ }^{d}$ & $(70.8)$ & & 0.001 & \\
\hline Lifelog data & 1,053 & $551(36.8)$ & $<$ & $<0.001$ \\
& $(70.2)$ & & 0.001 & \\
\hline Physical characteristics & 1,042 & $521(34.8)$ & $<$ & $<0.001$ \\
& $(69.5)$ & & 0.001 & \\
\hline Genetic information & 1,017 & $405(27.1)$ & $<$ & $<0.001$ \\
& $(67.8)$ & & 0.001 & \\
\hline Medical records & 966 & $413(27.6)$ & $<$ & $<0.001$ \\
& $(64.4)$ & & 0.001 & \\
\hline
\end{tabular}

${ }^{a}$ Adjusted for age (continuous), sex, education, and living area

${ }^{b}, c$ The value was calculated after changing the 4-point Likert scale to a dichotomous variable.

d Values included the people who responded that they will donate at least one type of health data.

\subsection{Factors associated with participation in a national registry for PM}

In the multivariate analysis, the cancer patients were three times likelier to participate in a national registry than the general population (95\% confidence interval [CI], 2.47-3.61). Across both groups, participants who had heard of PM (cancer patients: adjusted odds ratio $(\mathrm{aOR})=1.40,95 \% \mathrm{Cl}, 1.00-1.95$; general population: $\mathrm{aOR}=2.04,95 \% \mathrm{Cl}, 1.62-2.56$ ) and those who perceived more benefits of $\mathrm{PM}$ (cancer patients: $\mathrm{aOR}=2.48,95 \% \mathrm{Cl}, 1.88-3.27$; general population: $\mathrm{aOR}=1.34,95 \% \mathrm{Cl}, 1.05-1.71$ ) were likelier to express a willingness to participate in a national registry for PM (Table 4). Similarly, participants who perceived fewer barriers regarding PM were likelier to be willing to participate in a registry (cancer patients: $\mathrm{aOR}=1.57,95 \% \mathrm{Cl}, 1.18-2.08$ and general population: $\mathrm{aOR}=1.05,95 \% \mathrm{Cl}, 0.84-1.31)$. 
Table 4

Factors associated with willingness to participation in a national registry for precision medicine $(n=$ 2,996)

\begin{tabular}{|c|c|c|c|}
\hline & Overall & Cancer patients & General population \\
\hline & $(n=2,996)$ & $(n=1,500)$ & $(n=1,496)$ \\
\hline & Adjusted OR (95\% Cl) & Adjusted OR (95\% Cl) & Adjusted OR (95\% Cl) \\
\hline \multicolumn{4}{|l|}{ Type } \\
\hline General population & Reference & - & - \\
\hline Cancer patients & $2.98(2.47,3.61)$ & - & - \\
\hline Age (years) & $1.00(1.00,1.01)$ & $0.99(0.98,1.01)$ & $1.00(1.00,1.01)$ \\
\hline \multicolumn{4}{|l|}{ Sex } \\
\hline Male & Reference & Reference & Reference \\
\hline Female & $0.87(0.74,1.02)$ & $0.70(0.52,0.92)$ & $1.00(0.81,1.23)$ \\
\hline \multicolumn{4}{|l|}{ Education level } \\
\hline$\leq$ High school & Reference & Reference & Reference \\
\hline$\geq$ College & $0.91(0.77,1.08)$ & $0.63(0.47,0.83)$ & $1.16(0.94,1.45)$ \\
\hline \multicolumn{4}{|l|}{ Area of residence } \\
\hline Non-metropolitan & Reference & Reference & Reference \\
\hline Metropolitan & $1.22(1.02,1.44)$ & $1.41(1.09,1.84)$ & $1.14(0.91,1.43)$ \\
\hline \multicolumn{4}{|l|}{ Heard of it before } \\
\hline No & Reference & Reference & Reference \\
\hline Yes & $1.79(1.48,2.16)$ & $1.40(1.00,1.95)$ & $2.04(1.62,2.56)$ \\
\hline \multicolumn{4}{|l|}{ Knowledge } \\
\hline Limited & Reference & Reference & Reference \\
\hline Adequate & $0.99(0.84,1.17)$ & $1.12(0.86,1.46)$ & $0.90(0.72,1.12)$ \\
\hline \multicolumn{4}{|l|}{ Perceived benefits ${ }^{a}$} \\
\hline Low & Reference & Reference & Reference \\
\hline High & $1.81(1.51,2.17)$ & $2.48(1.88,3.27)$ & $1.34(1.05,1.71)$ \\
\hline
\end{tabular}




\section{Perceived barriers ${ }^{b}$}

\begin{tabular}{|cccc|}
\hline High & Reference & Reference & Reference \\
\hline Low & $1.31(1.10,1.55)$ & $1.57(1.18,2.08)$ & $1.05(0.84,1.31)$ \\
\hline a, b A value lower than 3 was stratified as "Low" based on the median of values of the whole sample. \\
\hline OR, odds ratio; $\mathrm{Cl}$, confidence interval & & \\
\hline
\end{tabular}

\section{Discussion And Conclusion}

\subsection{Discussion}

Nearly, one-third of the cancer patients and the general population were heard about PM and knew its concept correctly. The general Nevertheless, most of both two groups agreed that PM may be beneficial in terms of disease risk assessment, disease detection, and therapeutic effect improvement. Specially, cancer patients were more likely to have greater perceived benefits of PM and higher willingness to participate in a national registry for PM than the general population. However, fewer study participants in both groups said they would like to share their personal health data for PM, compared to the number of people who are willing to participate. In multivariable analysis, having heard of PM before, and perceiving a greater number of benefits and fewer barriers were associated with a willingness to participate in a national registry for PM.

In our study, only about one-third of the cancer patients and the general population chose the correct definition of PM; around half of them misunderstood the meaning of 'precision' in PM for the use of more fine-tuned medical devices. Other similar studies presented that over two-third of public were not familiar with the term 'precision medicine' or 'personalized medicine' [22-24]. And a Korean study conducted in 2018 reported that about one in ten people had heard of PM and what it is [25]. In a systematic review, low familiarity with PM was one of the barriers to public use of PM [26], and another study the familiarity was significant predictor of willingness to participate in PM research [24]. This low familiarity might be due to a paucity of related information. Although, around half of the cancer patients in our study had heard of PM from healthcare professionals, a majority of them had acquired information through either mass media or the Internet. In the general population, these channels were also main sources of PMrelated information, and similar studies supported our findings [24, 25]. These sources are generally easy and useful to access rapidly health information they need to find; however, credibility of the online information is controversial $[27,28]$. Therefore, it would be important to consider how to communicate accurate and credible information about PM through those channels, or what new channel, such as YouTube or other social media platforms, are effective in delivering the new information to the public. 
Most study population agreed with the benefits of PM, greater perceived benefits of PM were significantly associated with participating a national registry for PM. Especially, over $75 \%$ of the cancer patients and $55 \%$ of those in the general population expressed a willingness to participate in a national registry for PM, consistent with previous studies. In a survey of 2,601 people from the general population in the US, $54 \%$ expressed a willingness to participate in the Precision Medicine Initiative cohort study [29]. In another survey of 203 patients in the US, 69\% expressed a willingness to contribute to a biobank study, a concept similar to PM [30]. A Korean study conducted in 2018 reported $83.5 \%$ of adults recruited from online panel said they would participate in PM research, which was higher than our results [25]. This might be due to different sampling method or administration way of survey [25]. Cancer patients may be more willing to participate because they may expect practically effective benefits from PM for better treatment options and outcomes. It may also affect their positive attitudes toward PM that cancer patients have chances experience a certain level of PM during diagnosis and treatment, such as genetic testing or targeted therapy.

However, it may need to be careful because their positive attitudes or reactions toward PM can be due to vague expectations. For instance, less than one-third of the participants had heard of PM and most of them did not know the correct definition. Also, when we asked study participants about willingness to share their personal health data for PM, much less percentage of the study participants in both groups said they would like to share their personal health data for PM compared to the percentage of the study participants who had willingness to participate in a national registry. Although we did not ask specific reasons for not-sharing personal health data, it might have been reflecting their barriers related to privacy; it appears hold true in the general population compared to cancer patients. It might show indirectly the gap between intention and actual behavior. In general, privacy concern is well-known barriers to participating clinical studies $[23,26]$. Alternately it might need to mind the gap between individual intention and actual behavior. Generally, the hypothetical willingness rate differs from the actual participation rate [15], clinical research is often viewed with negativity and distrust, with members of the public believing that participants of clinical research are merely guinea pigs [31-33]. A national survey in Australia also mentioned that a high level of trust or strong belief in research was associated with a willingness to participate in biobank research for PM [13]. Another study reported that specifying the purpose of the information was the main factor of the willingness to share individual health data for clinical study [34]. Therefore, before asking participating in PM research, it might need to be prepared to clearly explain what roles would be required and what values could be expected by participating in PM research rather than just explaining what it is.

Our study has several limitations. First, it is a cross-sectional study, and the directions of the associations between willingness, knowledge, and attitude could be interchangeable. Second, most of the data were collected through self-reports, and participants may have overestimated their willingness to participate in a national registry for PM. Third, the participants' knowledge was measured using a single questionnaire with multiple choice, which may not reflect accurately the knowledge levels on PM. Further, it would not be possible to evaluate one's knowledge on PM merely by asking for a definition, as PM is a very broad 
concept. Finally, the results of our study may not be generalizable to other countries with different sociocultural perspectives.

\subsection{Conclusion}

In conclusion, cancer patients as the primary beneficiary group of PM more agreed various benefits associated with PM and showed higher willingness to participate in a national registry for PM compare to the general population. However, both cancer patients and the general population are still not wellinformed about it. Additionally, it may need to be careful whether their positive attitudes and hypothetical willingness to participate could be due to vague expectations resulting from a lack of understanding of PM. Considerable work needs to put in to educate the public and advocate participation in studies on PM. Especially, healthcare professionals, researchers, governments, and policymakers need to consider effective ways to inform the public, including cancer patients, what roles can be required and what values can be achieved by participating in PM-related studies.

\section{Abbreviations}

PM, precision medicine; $\mathrm{Cl}$, confidence interval; aOR, adjusted odds ratio; NR, National Research Council; US, United States

\section{Declarations}

Ethics approval and consent to participate: All procedures in the study involving human participants were carried out in accordance with the ethical standards of the international and/ or national research committee and with the 1964 Helsinki Declaration and its later amendments or comparable guidelines. The study was reviewed and approved by the institutional review boards of the National Cancer Center Korea (NCC 2016-0256) and the Samsung Medical Center (SMC 2016-12-040). All individual participants included in the study provided written informed consent.

Consent for publication: Not applicable

Availability of data and materials: The datasets used and/or analysed during the current study available from the corresponding author on reasonable request.

Competing interests: The authors have declared that no competing interests exist.

Funding: This research was supported by a grant from the National R\&D Program for Cancer Control, Ministry of Health and Welfare, Republic of Korea (no. 1520240)

\section{Author contributions:}

Conceptualization: M Lee, J Cho, SY Kong, J Yoon, D Kang, KS Choi, SY Shin, HJ Seo, SY Jung, MC Lim, ES Lee, and YJ Chang; 
Methodology: M Lee, J Cho, SY Kong, J Yoon, D Kang, KS Choi, SY Shin, HJ Seo, SY Jung, MC Lim, ES Lee, and YJ Chang;

Investigation: M Lee, J Yoon, SY Kong, and YJ Chang;

Formal analysis: M Lee, J Cho, and D Kang;

Writing-original draft preparation: M Lee, J Cho, SY Kong, and D Kang;

Writing-review and editing: M Lee, J Cho, SY Kong, J Yoon, D Kang, KS Choi, SY Shin, HJ Seo, SY Jung, MC Lim, ES Lee, and YJ Chang;

Funding acquisition: ES Lee and YJ Chang.

All authors have read and agreed to the published version of the manuscript.

M Lee, Mangyeong Lee; J Cho, Juhee Cho; SY Kong, Sun-Young Kong; J Yoon, Junghee Yoon; D Kang, Danbee Kang; KS Choi, Kui Son Choi; SY Shin, Soo-Yong Shin; HJ Seo, Hwa Jeong Seo; SY Jung, So-Youn Jung; MC Lim, Myong Cheol Lim; ES Lee, Eun Sook Lee; YJ Chang, Yoon Jung Chang

Acknowledgements: Not applicable

\section{References}

1. Mullard A: \$215 million precision-medicine initiative takes shape. Nature Reviews Drug Discovery 2015, 14:155-156.

2. Ashley EA: The precision medicine initiative: A new national effort. J Am Med Assoc 2015, 313(21):2119-2120.

3. Collins FS, Varmus H: A new initiative on precision medicine. New England Journal of Medicine 2015, 372(9):793-795.

4. Tomczak K, Czerwińska P, Wiznerowicz M: The Cancer Genome Atlas (TCGA): an immeasurable source of knowledge. Contemp Oncol 2015, 19(1A):A68.

5. Björkholm M, Ohm L, Eloranta S, Derolf Å, Hultcrantz M, Sjöberg J, Andersson T, Höglund M, Richter J, Landgren O: Success story of targeted therapy in chronic myeloid leukemia: a population-based study of patients diagnosed in Sweden from 1973 to 2008. J Clin Oncol 2011, 29(18):2514.

6. Chin L, Andersen JN, Futreal PA: Cancer genomics: from discovery science to personalized medicine. Nat Med 2011, 17:297.

7. Gonzalez-Angulo AM, Hennessy BT, Mills GB: Future of personalized medicine in oncology: a systems biology approach. J Clin Oncol 2010, 28(16):2777.

8. Khoury MJ, lademarco MF, Riley WT: Precision public health for the era of precision medicine. Am J Prev Med 2016, 50(3):398. 
9. Asano H: Personalized and Precision Medicine in Japan. 2017, 43.

10. Gottweis H, Gaskell G, Starkbaum J: Connecting the public with biobank research: reciprocity matters. Nature Reviews Genetics 2011, 12(11):738.

11. Lévy Y: Genomic medicine 2025: France in the race for precision medicine. The Lancet, 388(10062):2872.

12. Zhang L, Wang H, Li Q, Zhao M-H, Zhan Q-M: Big data and medical research in China. BMJ 2018, 360.

13. Critchley CR, Nicol D, Otlowski MFA, Stranger MJA: Predicting intention to biobank: a national survey. The European Journal of Public Health 2010, 22(1):139-144.

14. Sanderson SC, Brothers KB, Mercaldo ND, Clayton EW, Antommaria AHM, Aufox SA, Brilliant MH, Campos D, Carrell DS, Connolly J et al: Public Attitudes toward Consent and Data Sharing in Biobank Research: A Large Multi-site Experimental Survey in the US. The American Journal of Human Genetics 2017, 100(3):414-427.

15. Johnsson L, Helgesson G, Rafnar T, Halldorsdottir I, Chia K-S, Eriksson S, Hansson MG: Hypothetical and factual willingness to participate in biobank research. European Journal of Human Genetics 2010, 18(11):1261.

16. van Zon SK, Scholtens S, Reijneveld SA, Smidt N, Bültmann U: Active recruitment and limited participant-load related to high participation in large population-based biobank studies. J Clin Epidemiol 2016, 78:52-62.

17. National Research Council: Toward precision medicine: building a knowledge network for biomedical research and a new taxonomy of disease: National Academies Press; 2011.

18. Cantor D, Covell J, Davis T, Park I, Rizzo L: Health information national trends survey 2005 (HINTS 2005): Final Report. 2005.

19. What are some potential benefits of precision medicine and the Precision Medicine Initiative? [https://ghr.nlm.nih.gov/primer/precisionmedicine/potentialbenefits]

20. What are some of challenges facing precision medicine and the Precision Medicine Initiative? [https://ghr.nlm.nih.gov/primer/precisionmedicine/challenges]

21. Personalized Cancer Care: Where it Stands Today [https://www.cancer.org/latest-news/personalizedcancer-care-where-it-stands-today.html]

22. Eastman P: Survey: public awareness of personalized medicine low, but people do want to know more. Oncology Times 2014, 36(18):22-23.

23. Garfield S, Douglas MP, MacDonald KV, Marshall DA, Phillips KA: Consumer familiarity, perspectives and expected value of personalized medicine with a focus on applications in oncology. Per Med 2015, 12(1):13-22.

24. Moriarty K, Wolf SM, Veach PM, LeRoy B, MacFarlane IM, Zierhut HA: A roadmap for precision medicine research recruitment: empirical assessment of the public's willingness to participate. Per Med 2020, 17(05):345-359. 
25. Kim H, Kim HR, Kim S, Kim E, Kim SY, Park H-Y: Public Attitudes Toward Precision Medicine: A Nationwide Survey on Developing a National Cohort Program for Citizen Participation in the Republic of Korea. Frontiers in Genetics 2020, 11:283.

26. Holden C, Bignell L, Mukhopadhyay S, Jones C: The public perception of the facilitators and barriers to implementing personalized medicine: a systematic review. Per Med 2019, 16(5):409-420.

27. Eysenbach G, Powell J, Kuss O, Sa E-R: Empirical studies assessing the quality of health information for consumers on the world wide web: a systematic review. J Am Med Assoc 2002, 287(20):26912700.

28. Hesse BW, Nelson DE, Kreps GL, Croyle RT, Arora NK, Rimer BK, Viswanath K: Trust and sources of health information: the impact of the Internet and its implications for health care providers: findings from the first Health Information National Trends Survey. Arch Intern Med 2005, 165(22):2618-2624.

29. Kaufman DJ, Baker R, Milner LC, Devaney S, Hudson KL: A survey of US adults' opinions about conduct of a nationwide Precision Medicine Initiative $₫$ cohort study of genes and environment. PLOS One 2016, 11(8):e0160461.

30. Rahm AK, Wrenn M, Carroll NM, Feigelson HS: Biobanking for research: a survey of patient population attitudes and understanding. Journal of community genetics 2013, 4(4):445-450.

31. Braunstein JB, Sherber NS, Schulman SP, Ding EL, Powe NR: Race, medical researcher distrust, perceived harm, and willingness to participate in cardiovascular prevention trials. Medicine 2008, 87(1):1-9.

32. Gorelick PB, Harris Y, Burnett B, Bonecutter FJ: The recruitment triangle: reasons why African Americans enroll, refuse to enroll, or voluntarily withdraw from a clinical trial. An interim report from the African-American Antiplatelet Stroke Prevention Study (AAASPS). J Natl Med Assoc 1998, 90(3):141.

33. Quinn GP, Koskan A, Wells KJ, Gonzalez LE, Meade CD, Pozo CLP, Jacobsen PB: Cancer patients' fears related to clinical trial participation: a qualitative study. J Cancer Educ 2012, 27(2):257-262.

34. Grande D, Asch DA, Wan F, Bradbury AR, Jagsi R, Mitra N: Are patients with cancer less willing to share their health information? Privacy, sensitivity, and social purpose. J Oncol Pract 2015, 11(5):378-383.

\section{Supplementary Files}

This is a list of supplementary files associated with this preprint. Click to download.

- BMCPMSupplementaryMaterials0302.pdf 